\title{
ANTONIO RICCI EN MADRID: 1586-1635
}

Nuevas aportaciones documentales aclaran la vida del pintor Antonio Ricci en la Corte española desde su llegada a El Escorial junto a Federico Zuccari en 1586. Ricci trabajó como pintor en el entorno palaciego y estuvo involucrado desde el principio en el intento de creación de la Academia madrileña de pintores. Se detallan aquí su trabajo como tasador, su retrato del futuro Felipe IV o su cercana relación con un personaje tan singular como Jeronimo Gratti, el Caballero de Gracia.

Palabras clave: Antonio Ricci (c. 1565-c. 1635); Pintura Española; Retratistas del siglo XVII; Jeronimo Gratti, Caballero de Gracia (1516-1617); Academia madrileña de pintura.

Life of painter Antonio Ricci is studied by new documents from his arrived at Escorial with Federico Zuccari in 1586. Ricci worked in the Palace of Madrid and was involved in the birth of the Academy of Painting. Here are studied his work as Painter and Appraiser, or his portrait of Philip IV of Spain and his relationship with Jeronimo Gratti, Caballero de Gracia.

Key words: Antonio Ricci (c. 1565-c. 1635); Spanish Painting; 17th Century Portrait painters; Jeronimo Gratti, Caballero de Gracia (1516-1617); Academy of Painting in Madrid. 
La polifacética personalidad del pintor italiano afincado en Madrid Antonio Ricci, ha sido abordada en varias ocasiones por nuestra historiografía. Sin embargo, la multitud de tareas a las que dedicó su existencia y la diversidad de fuentes que lo mencionan, ha motivado que algunos estudios que abordan su figura no recojan la totalidad de informaciones a las que ha dado pie. En este trabajo pretendemos aunar las fuentes bibliográficas anteriores con nuevas aportaciones documentales que pongan al día la interesante personalidad de este singular artista, padre además de dos importantes pintores de la siguiente generación: el monje benedictino fray Juan Andrés Ricci (1600-1681) y el pintor real Francisco Ricci (1614-1685) ${ }^{1}$.

Casi bajo palio, como describe el padre Sigüenza, fue recibido Federico Zuccari a comienzos de 1586 en San Lorenzo de El Escorial. Iba acompañado de sus colaboradores: Tiberio Ronchi, Andrea Carrari, Bernardino Veneziano, Bartolomé Carducci y Antonio [Ricci] de Ancona ${ }^{2}$. Allí se asignaban a este último diez escudos como salario mensual ${ }^{3}$. Pero, como es bien sabido, las obras de Zuccari no gustaron en el entorno cortesano. Ni sus pinturas para el retablo mayor ni las imágenes al fresco que realizó junto a su equipo resultaron satisfactorias. Pocos meses después de su llegada fueron despedidos sus colaboradores y algo más tarde el mismo maestro ${ }^{4}$. El único que pareció contar con crédito suficiente para continuar trabajando en El Escorial fue Bartolomé Carducho (h. 1560-1608), que se había unido a Zuccari cuando éste había llegado a Florencia en 1578. Sin embargo, al regreso a Italia del maestro permaneció en España y se incorporó con éxito al grupo de ayudantes de Pellegrino Tibaldi, hasta convertirse más adelante en pintor real ${ }^{5}$.

Antonio Ricci, nacido en Ancona seguramente entre 1560 y $1565^{6}$, era paisano de Zuccari, quien procedía de la vecina localidad de Sant'Angelo in Vado y regresaría a su tierra al final de su vida, muriendo en la propia Ancona en $1609^{7}$. Por su parte, Antonio Ricci, al contrario que su maestro, decidió permanecer en España. Aunque Palomino no le dedica biografía propia, le denomina "muy buen pintor", mientras que Ceán Bermúdez le considera autor, dentro del grupo de

${ }^{1}$ Este estudio se encuadra en la investigación realizada como Tesis doctoral dedicada a uno de los hijos de Antonio Ricci, el también pintor y tratadista fray Juan Andrés Ricci: GARCíA LóPEZ, D., Arte y pensamiento en el Barroco: fray Juan Andrés Ricci de Guevara (1600-1681), Madrid, F.U.E. 2010; de nuevo quiero agradecer a las instituciones que con sus becas y ayudas a la investigación hicieron posible dicho estudio: Universidad Complutense de Madrid, Ministerio de Educación y Ciencia, Consejería de Educación de la Comunidad de Madrid, Museo Nacional del Prado y Academia de España en Roma.

${ }^{2}$ De SigüEnZA, J., La fundación del Monasterio de El Escorial, Madrid, Aguilar, 1988, p. 376; Zarco Cuevas, J., Pintores italianos en San Lorenzo el Real de El Escorial (1575-1613), Madrid, 1932, p. 196; sobre las impresiones del propio Zuccaro a su llegada a España Domínguez BordonA, J., "Federico Zuccaro en España", en Archivo Español de Arte y Arqueología, 1927, 7, pp. 77-89; ZucCARo, F., "Relación de un viaje al Escorial, Aranjuez y Toledo", en SÁNCHEZ CAntón, F. J., Fuentes literarias para la historia del arte español, Madrid, 1923-41, t. V, pp. 243-260.

3 Zarco Cuevas, J., op. cit., p. 203.

${ }^{4}$ Babelon, J., "Federico Zuccaro à l'Escurial", en Revue de l'Art Ancien et Moderne, 1920, pp. 263-278; MulcAHY, R., A la mayor gloria de Dios y del Rey: la decoración de la Real Basílica del Monasterio de El Escorial, Madrid, 1992, pp. 113 y ss.; ZuCCARI, A., "Federico Zuccari e l'Escorial", en Cleri, B. (ed.), Federico Zuccari. Le idee, gli scritti [Actas del Congreso Pésaro-Urbino, 1995], Milán, 1997, pp. 21-44; BRunNer, M., "Federico Zuccaro in Spanien (1585-1588)", en Weddigen, T. (ed.), Federico Zuccaro, Basilea, 2000, pp. 17-42; Gampr, A. C., "Zuccaro am Escorial oder: Scheitern der Kunst und Triumph des Werkes", en Ibid., pp. 117-145.

5 Angulo Íñiguez, D. y Pérez SÁnchez, A. E., Escuela madrileña del primer tercio del Siglo XVII, Madrid, 1969 , pp. 14-46; Brasas, J. C., "Nuevos cuadros firmados de Bartolomé Carducho", en Boletín del Seminario de Arte y Arqueología, 1973, pp. 246-8; Cat. Exp. Firenze e la Toscana: Dei Medici nell'Europa del '500, Florencia, 1980, n. ${ }^{\circ}$ 149; Lapuerta Montoya, M., "Bartolomé Carducho y Juan de Bolonia: arte y diplomacia en la Corte de Felipe III", en Anales de Historia del Arte, 1997, pp. 157-182.

${ }^{6}$ Angulo Íñiguez, D. y Pérez SÁnchez, A. E., op. cit., p. 57.

7 Sobre Zuccari, los diferentes estudios en Cleri, B. (ed.), Federico Zuccari, op. cit.; y Weddigen, T. (ed.), op. cit.

${ }^{8}$ Palomino, A., El Museo Pictórico y escala óptica, Madrid, Aguilar, 1988, v. III, p. 335. 
Zuccari, de los frescos del patio de los Evangelistas que después fueron cubiertos por las pinturas de Tibaldi y su taller ${ }^{9}$. Palomino recoge también la noticia de su boda en la iglesia de San Ginés, el 18 de septiembre de 1588, con Gabriela de Chaves o Guevara - pues en la documentación utilizará ambos apellidos indistintamente, mientras que Juan Andrés optará por utilizar el Guevara como segundo apellido-. Ella era natural de Madrid ${ }^{10}$, huérfana de un dorador de la Corte, tal y como recogen las capitulaciones matrimoniales de junio de ese mismo año ${ }^{11}$. No sabía escribir y ni siquiera firmar, como se señala en el primer contrato conocido de su hijo Juan Andrés Ricci con el convento de la Merced de Madrid, que comentaremos más adelante, donde la madre está entre los avalistas: "la dicha gabriela de guebara por no sauer firmar".

Aparte de los encargos puntuales de la Corte que luego comentaremos, las noticias que poseemos evidencian que Antonio Ricci decidió abrir un taller propio en Madrid. Así lo atestiguan las sucesivas compras que en 1592 realizó el patriarca Juan de Ribera (1532-1611), primero tres obras religiosas en abril ${ }^{12}$, y hasta doce retratos de personajes reales en el mes de mayo, posiblemente copias de los originales perdidos en el Palacio de El Pardo en $1604^{13}$. La mayoría de todas estas pinturas permanecen aún en el Colegio del Patriarca, adonde fueron destinadas tras su compra ${ }^{14}$. Su baja calidad, muy diferente a otras pinturas que conocemos de su mano, puede significar que Antonio Ricci contaba con otros colaboradores en su obrador, necesarios para satisfacer la demanda de sus patronos, casi siempre a través de retratos o copias de retratos como fue esencialmente conocido. Aunque también realizó otras pinturas de gran auge en la época, por ejemplo imitando o copiando los cuadros de los Bassano que hacían furor entre los coleccionistas hispanos ${ }^{15}$. Posteriormente, en 1594, se le cita en la venta de un censo ${ }^{16} \mathrm{y}$, siguiendo con las actividades de su taller, al año siguiente se documenta la llegada de un aprendiz llamado Antonio López ${ }^{17}$.

En 1594 también aparece vinculado a un importante personaje de la Corte madrileña: Jacopo Gratii (1517-1619), más conocido como el Caballero de Gracia ${ }^{18}$. Por la documentación conservada, Antonio Ricci debió mantener una cercana y duradera relación con el antiguo diplomático de Módena. El veintiséis de junio de 1594 Antonio Ricci, junto a su mujer, fundan un censo en el que el Caballero de Gracia se compromete como fiador ${ }^{19}$. Aún más interesante es la cláusula del testamento de Gratii del 20 de septiembre de 1602, en el que éste manda que "se paguen a Antonio Ricci pintor doscientos ducados, los cuales le debo para después de mis dias y se le en-

9 CeÁn Bermúdez, J. A., Diccionario histórico de los más ilustres profesores de las bellas artes en España, Madrid, Viuda de Ibarra, 1800, t. IV, p. 202.

${ }^{10}$ Palomino, A., op. cit., III, p. 335; también lo recoge Cé́n BermúdeZ, J. A., op. cit., t. IV, p. 203.

11 Pérez Pastor, C., "Colección de documentos inéditos para la historia de las bellas artes en España", en $M e$ morias de la Real Academia Española, t. XI, 1914, p. 54, este autor también incluye el documento de 29-8-1588 del poder para el cobro de la dote de la esposa del monasterio de Santa Clara de Madrid (pp. 54-55), en Archivo Histórico de Protocolos de Madrid (en adelante A.H.P.M.), protocolo n. ${ }^{\circ} 864$; de ese mismo año es el Censo que realiza Antonio Ricci "sobre unas casas en Madrid", A.H.P.M., protocolo n. ${ }^{\circ}$ 1396, fol. 819, ante el escribano Gabriel de Rojas.

12 Benito Doménech, F., "A propósito de unos cuadros inéditos de Antonio Ricci”, en Archivo Español de Arte, 1979, pp. 350-5.

13 Benito Doménech, F., Pintura y pintores en el Real Colegio de Corpus Christi, Valencia, 1980, pp. 350-355 y $142-3$.

${ }^{14}$ Ibid., n. ${ }^{\text {os }} 212-222$.

15 Así ocurría con una de las tres primeras pinturas solicitadas por el patriarca Ribera: Parábola del rico Epulón y el pobre Lázaro; también Bartolomé Carducho se dedicaba al comercio de este tipo de pinturas; sobre su mercado en España véase Falomir Faus, M., Cat. Exp. Los Bassano en la España del Siglo de Oro, Madrid, Museo del Prado, 2001, p. 23.

16 23-8-1594, en Pérez PASTOR, C., op. cit., p. 65.

17 5-3-1595, también en Pérez Pastor, C., op. cit., p. 72.

18 Roscales Olea, G., El Caballero de Gracia. Más de cien años de aventura, Madrid, 1989.

19 A.H.P.M., Escribano Baltasar Dejas, Protocolo, n. ${ }^{\circ}$ 810, fols. 664-672. 
treguen ciertos cuadros y pinturas que así mismo se le han de dar después de mis dias, conforme a una obligación que contra mì tiene a que me refiero" ${ }^{20}$. Así podemos conocer que Ricci prestaba cuadros de su obrador para las celebraciones del Caballero de Gracia ${ }^{21}$, concretamente alega, en 1604 , que son "quince retablos y pinturas que yo tengo prestadas al caballero jacome de gracia" 22 . A través de esta estrecha relación y de la conocida habilidad del artista en los retratos, se puede especular sobre la posible autoría de Antonio Ricci del pequeño retrato del Caballero de Gracia conservado en el Oratorio y que todavía se encuentra en discusión ${ }^{23}$.

Antonio Ricci también aparece frecuentemente en la documentación de la parroquia de San Sebastián de Madrid, fundamentalmente por el bautizo de sus numerosos hijos: José, en 1596, Romualda, en 1597, Polonia, en 1599, Juan, en 1600, Catalina, en 1602, Adán, en 1604, de nuevo otra Catalina, en 1607, Gabriela, en 1610 y, finalmente, Francisco, en $1614^{24}$; mientras que en 1607 murió su hija María y al año siguiente lo haría Francisco, un hermano homónimo del posteriormente célebre pintor ${ }^{25}$. Hay que añadir a éstos una Ana Ricci, casada con Cristóbal Esteban, que aparecerá posteriormente en la documentación familiar ${ }^{26}$. Ambos cónyuges aparecen como fiadores del pintor Juan Andrés Ricci en el contrato de éste firmó con el convento de los mercedarios en 1625, donde a Ana Ricci se la define como "hermana" del joven pintor ${ }^{27}$. También aparece junto a su padre Antonio, por ejemplo, en la compra de varias alhajas en $1622^{28}$.

Asimismo es interesante señalar que mientras en el bautismo del primer hijo, José, el 24 de febrero de 1596, se cita como domicilio el "hospital de los italianos"29, en 1604 se informa que Adán nació el 9 de noviembre ya en las casas de la Carrera de San Jerónimo ${ }^{30}$, domicilio donde se citará a Antonio Ricci de aquí en adelante. En todo caso, el Hospital se encontraba en la misma calle, a sólo unos metros de donde posteriormente se suele mencionar a los Ricci, en una casa de la Carrera de San Jerónimo frente a la calle del Lobo. La pertenencia de Antonio Ricci a la parroquia de San Sebastián es también indicativa del medio en el que se relacionaba. Situada en

20 A.H.P.M., Escribano Juan Correas, Protocolo, n. ${ }^{\circ} 2420$, fols. 260-3.

21 Sanabria, J. M., El Caballero de Gracia y Madrid, Madrid, 2004, p. 286; agradezco al autor, don José María Sanabria, su ayuda para encuadrar la relación de Antonio Ricci y el Caballero de Gracia.

22 A.H.P.M., escribano Juan de Zamora, protocolo, n. ${ }^{\circ}$ 1738, fol. 189, 23-6-1604.

${ }^{23}$ Roscales Olea, G., "Noticias sobre la pintura del Real Oratorio del Caballero de Gracia", en Academia, 1994, n. ${ }^{\circ} 79$, pp. 419-460 (pp. 430-433).

${ }^{24}$ Hay que desmentir una vez más la noticia de Cé́n Bermúdez, J. A., que hacía nacer a Francisco en 1608 (Diccionario..., op. cit., t. IV, p. 203); es posible que Ceán confundiese al futuro pintor real con un hermano homónimo que moriría todavía niño en 1608, como seguidamente se dirá.

${ }^{25}$ MAzÓn de la Torre, M. A., "Las partidas de Bautismo de Eugenio Cajés, de Félix Castelo, de los hermanos Rizi y otras noticias sobre artistas madrileños de la primera mitad del siglo XVIII", en Archivo Español de Arte, XLIV, 1971, pp. 413-425 (p. 419); FERNÁNDEZ GARCÍA, M., "Pintores de los siglos XVI y XVII que fueron feligreses de la parroquia de San Sebastián", en Anales del Instituto de Estudios Madrileños, XVII, 1980, pp. 109-135 (p. 130); FernÁNDEZ GARCíA, M., Parroquia madrileña de San Sebastián. Algunos personajes de su archivo, Madrid, 1995, pp. 185-6.

${ }^{26}$ Quizá es la nacida en 1604 y que se debió inscribir por error como "Ana Ricci hija de Francisco Ricci pintor", según Fernández García, M., Parroquias madrileñas de San Martín y San Pedro El Real. Algunos personajes de su Archivo, Madrid, 2004, pp. 14-17.

27 A.H.P.M., escribano Gregorio de Soto, Protocolo n. ${ }^{\circ}$ 2873, fols. 394-399; contrato ya recogido en Notas tomadas por don Alejandro Martin Ortega de escrituras del Archivo Histórico de Protocolos de Madrid, tomo IV, Índices elaborados por César Augusto Palomino Tossas, 1991, fols. 227 y 227v. (ejemplar mecanografiado depositado en el A.H.P.M.); MARÍAs Franco, F., "La vida errante del monje fray Juan Andrés Ricci de Guevara (1600-1681)", en RicCI, J. A., La Pintura Sabia (1659), ed. de Fernando Marías Franco y Felipe Pereda Espeso, Toledo, 2002, pp. 24-41 (p. 26) y GarCía LóPez, D., op. cit., pp. 60-62.

28 A.H.P.M., escribano Ruiz de Tapia, Protocolo n. ${ }^{\circ} 2325$, s.f.

${ }^{29}$ Fernández García, M., Parroquia madrileña..., op. cit., p. 185.

30 Ibid. 
pleno barrio de los artistas y literatos, era también el templo al que acudían compañeros pintores de su círculo: Romulo Cincinato, Bartolomé y Vicente Carducho, Fabrizio y Félix Castelo, Patricio y Eugenio Cajés o Luis de Carvajal entre otros.

En 1600, Antonio Ricci realiza, junto al pintor real Francisco López -al que nos volveremos a encontrar junto a Ricci en la firma de la Academia de pintores-, la tasación de una de las pinturas ejecutadas por Patricio Cajés con motivo de la entrada en Madrid de la reina Margarita de Austria $^{31}$. De 1603 es su firma en el retrato de Sor María de la Cruz de las Descalzas Reales ${ }^{32}$, que confirmaría su actividad de retratista para la Corte, tal y como se recoge en los inventarios de 1621 cuando se describen varias de sus pinturas entre los retratos que adornaban el Guardajoyas del Alcázar Real ${ }^{33}$. Al año siguiente, en 1622, aparece como tasador por parte del Rey para valorar treinta y cinco retratos realizados por Pantoja de la Cruz en El Pardo, mientras por parte de los herederos del pintor vallisoletano tasó Jerónimo López ${ }^{34}$. Precisamente para el Convento del Cristo de El Pardo se le encargó a Ricci una pintura de Nuestra Señora de los Ángeles que sustituyera a la realizada por Bartolomé González ${ }^{35}$. No hay duda, por lo tanto, de que Antonio Ricci ocupó un papel activo entre los artistas cortesanos del momento. A esto hay que sumar la declaración de su hijo Francisco Ricci bastantes años después, describiendo a su padre como pintor de "Camara del rey Sr. Rey Phelipe Quarto siendo Principe, como parece de los retratos de aquel tiempo, assi en el Escurial, como en el Pasadiço de la Encarnaçion y otras partes" 36. Efectivamente, por la documentación palaciega sabemos que en 1611 se le encargan varios retratos. El 19 de abril se le abonan 400 reales "A cuenta de lo que montaren los retratos que por mandado de Su Mag[esta]d"37, y en junio entrega ya un retrato del futuro Felipe IV:

"En Madrid a 12 de junio de 1611 Entrego hecho Vn retrato de Pinzel al olio sobre lienzo entero del Prinzipe nro sr armado con un baston en la mano... pintado un leon muy grande" ${ }^{" 38}$.

Confirmando lo declarado por Francisco Ricci, sabemos que dicho lienzo adornaba el Alcázar de Madrid. En 1621 se encontraba en la "Galeria de afuera" y en 1636 en la "Pieza en que duerme su majestad en el Cuarto Bajo de Verano":

31 Lapuerta Montoya, M., Los pintores de la Corte de Felipe III, Madrid, 2002, p. 77, documento reproducido en p. 533.

32 Angulo Íñiguez, D. y Pérez SÁnchez, A. E., op. cit., p. 63; recientemente se ha atribuido a Antonio Ricci otro cuadro del monasterio de las Descalzas Reales, el Retrato de la emperatriz María que tradicionalmente se había vinculado con Juan Pantoja de la Cruz, así lo cree Kusche, M., Juan Pantoja de la Cruz y sus seguidores B. González, R. de Villandrando y A. López Polanco, Madrid, FAH, 2007, pp. 29 y 411; por mi parte me decanto por la atribución tradicional a Pantoja que se remonta a CEÁn BERMúdez, J. A., op. cit., IV, p. 46; y que ha seguido unánimemente la historiografía posterior, Tormo, E., En las Descalzas Reales, Madrid, 1915, pp. 25, 167 y 194; Kusche, M., Juan Pantoja de la Cruz, Madrid, 1964, p. 196; Bonet Correa, A., Monasterios Reales del Patrimonio Nacional, 1984, p. 35; Cat. Exp. Felipe II. Un monarca y su época. Las tierras y los hombres del Rey, Valladolid, 1998, p. 203, n. ${ }^{\circ} 10$.

33 Pinturas que no figuraban en el inventario de 1617, véase De Madrazo, P., Viaje Artístico de tres Siglos por las colecciones de cuadros de los reyes de España, Barcelona, 1884, pp. 79-80; ANGulo Íñiguez, D. y Pérez SÁnchez, A. E., op. cit., p. 64.

${ }^{34}$ Lapuerta Montoya, M., op. cit., p. 521, doc. n. ${ }^{\text {os }} 110$ y 111; Kusche, M., Juan Pantoja de la Cruz y sus seguidores..., op. cit., pp. 156-160.

35 Blanco García, G., Nuestra señora de los ángeles (inédito), 1981, p. 147; De Navascués Benlloch, P. y Conde de Beroldingen Geyr, C. (dirs.), Cat. Exp. El legado de un mecenas. Pintura española del Museo Marqués de Cerralbo, Madrid, 1998, p. 38; Kusche, M., Juan Pantoja de la Cruz y sus seguidores..., op. cit., p. 340.

36 Simón, J., "Francisco Rizi, postergado", en Archivo Español de Arte, 1945, pp. 308-309.

37 Archivo General del Palacio Real de Madrid (en adelante A.G.P.R.M.), Expedientes Personales, "Ricci, Antonio", caja 878, exp. 39: "A cuenta de lo que montaren los retratos que por mandado de Su Magd y de horden de... De quien rez. ${ }^{\circ}$ los 400 reales... carta de pago firmada de su nombre en Madrid a 19 de abrill de 1611 años".

38 Ibid. 
"otro lienzo de pincel al óleo, con el retrato del Rey Señor siendo Príncipe, cuerpo entero, armado y a lo alto dos ángeles con un jeroglíficos, y a los pies un leon. Hizole Antonio Ricci" ${ }^{\prime 3}$.

La actividad de Antonio Ricci como retratista de las personas reales no se limitó a sus obras para la Corte. Como había hecho para el Colegio del Patriarca de Valencia, Ricci exportó efigies regias a otros coleccionistas. Así aparece, por ejemplo, en el inventario de bienes realizado a la muerte del capitán e ingeniero de Su Majestad Jerónimo de Soto, concretamente un "retrato de felipe terzero... con un perro Sin moldura de mano de antonio Ricci" ${ }^{40}$.

También en 1603 encontramos a Antonio Ricci en el importante protocolo que establecen los pintores para defender sus intereses y crear una Academia llamada del "Señor San Lucas"41, primera asociación de este tipo de la que se tiene noticia en la Corte. Al año siguiente aparece como fiador del pintor Martín Fernández de Chinchón, quien "se obliga a hacer un retablo para la capilla del licenciado Morillas... difunto que fue del consejo del rey, que esta en san jeronimo el real" 42 . Ese mismo año de 1604 se obliga como "pintor de nacion italiano natural de la ciudad de Ancona, vecino de Madrid", a pagar una deuda de 3.000 ducados contraída con "Margarita Yadanga", criada de la recientemente fallecida Emperatriz María de Austria, en la que hace mención a diversos pagos que se le deben, entre los que aparece la cita al Caballero de Gracia ${ }^{43}$. Esta deuda llevará al pintor a prisión, donde se encuentra en diciembre de 1605, aunque conseguirá salir de ella al encontrar varios fiadores ${ }^{44}$.

En julio de 1606, Ricci es llamado junto al escultor Juan Muñoz para reconocer la imagen de la Soledad de Gaspar Becerra de la cofradía del Convento de la Victoria, que era objeto de pleito ${ }^{45}$. Como veremos más adelante, dicho convento aparece vinculado como lugar de reunión

39 Quadros y otras cosas que tiene Su Majestad Felipe IV en este Alcázar de Madrid. Año de 1636, ed. de Gloria Martínez Leiva y Ángel Rodríguez Rebollo, Madrid, F.U.E., 2007, p. 193, n. ${ }^{\circ}$ 1880; en 1636 se describe como "El Rei Nuestro Señor. Otro retrato al olio del Rei, Nuestro Señor, Don Phelipe cuarto siendo niño, cuerpo entero, armado y con calças blancas, y en lo alto dos ángeles con unos gerolíficos y en lo bajo de unas gradas un león. Tiene moldura dorada y negra" (p. 105, n. ${ }^{\circ} 877$ ).

40 A.H.P.M., 16/2/1630, ante el escribano Antonio Herrero, protocolo n. ${ }^{\circ}$ 5599, fol. 710, inventario realizado por el pintor Francisco Ruiz, que tasa el cuadro de Antonio Ricci en 220 reales.

${ }^{41}$ Matilla Tascón, A., "La Academia madrileña de San Lucas," en Goya, n. ${ }^{\text {os }} 161-162$, 1981, pp. 260-265; PéreZ SÁnchez, A. E., "La academia madrileña de 1603 y sus fundadores", en Boletín del Seminario de Estudios de Arte y Arqueología, 1982, pp. 281-289.

42 A.H.P.M., 19/7/1604, ante el escribano Santiago Fernández, protocolo n. ${ }^{\circ}$ 1990, fol. 992, 19-7-1604.

43 A.H.P.M., 23/6/1604, ante el escribano Juan de Zamora, protocolo n. ${ }^{\circ} 1738$, fol. 189, 23-6-1604.

44 A.H.P.M., 5/12/1605, ante el escribano Santiago Fernández, protocolo n. ${ }^{\circ}$ 1994, fols. 1339 y 1553; ver también PÉrez PASTOR, C., op. cit., pp. 115-116.

${ }^{45}$ La imagen se disputaba entre la Cofradía de Nuestra Señora de la Soledad y los conventuales del monasterio, así se provee un decreto en el que "mandauan al Corregidor de Madrid o a su Lugarteniente, que acompañado de vn escriuano, vn escultor, y vn pintor viniesse a este Conuento de la Vitoria, y con el recato, veneracion, y decencia possible entrassen en la Capilla de nuestra Señora de la Soledad, y la hiziessen desnudar, y les embiassen por testimonio firmado de todos como era el cuerpo de la Santa Imagen. En cumplimiento de lo qual vinieron el Licenciado Perez de Lara, Teniente que era de Corregidor, Ioseph de Palomares escriuano del Numero de Mdrid, Iuan Muñoz escultor, y Antonio de Riche pintor... Hizose este examen a cinco dias del mes de Iulio de 1606", en ArEs, A., Discurso del ilustre origen y grandes excelencias de la misteriosa Imagen de nuestra señora de la Soledad del convento de la Victoria de Madrid..., Madrid, 1640, fols. 157v.-158; en SÁNCHEZ CANTÓN, F. J., op. cit., vol. V, p. 476, se señala por error que la cita se encuentra en el fol. 157 de la obra de fray Antonio Ares. Posteriormente, Francisco Ricci también colaboraría en la decoración en la capilla de la Virgen con el cuadro que coronaba el retablo, en DE OÑa, T., Fénix de los ingenios que renace de las plausibles cenizas del certamen que se dedicó a la... imagen de N.S. de la Soledad en la célebre translación a su sumptuossa capilla, Madrid, 1664, fol. 31: "El complemento insigne de esta fábrica maravillosa puso la envidia de Ceusis, la emulación de Parrasio, el Apeles de España en una pintura de perspectiva y dibuxo del Des- 
de la Academia de los pintores madrileños desde su formación en 1603. En noviembre de 1606 se firmará el contrato que cede definitivamente este lugar para las reuniones académicas a cambio de algunas contraprestaciones, que podrían ya aventurarse en este trabajo de Ricci para el convento. Y todo parece indicar que durante los años siguientes, mientras este tipo de agrupación artística gozó de continuidad, el convento de la Victoria sirvió de acomodo a los pintores.

Ese mismo 1606 vuelve a aparecer Antonio Ricci cuando otorga un poder para el cobro de 420 ducados por unas pinturas que había vendido al vecino de Sevilla don Juan Vicentelo ${ }^{46}$. Sobre su posible estancia en Valladolid junto a la Corte de Felipe III, que allí se asentó entre 1601 y 1606, no hay ningún dato concreto hasta ahora, como los que sí certifican la presencia de los hermanos Carducho. Por ello se ha deducido que, a diferencia de Ricci, ambos no se encontraran entre los firmantes de la Academia de Pintores de 1603. La cantidad de noticias de Antonio Ricci en Madrid durante estos años, tal y como venimos señalando, pondrían en duda esa estancia en la efímera corte vallisoletana. Sin embargo, la presencia de "once lienços de bara y dos terçias, con sus molduras de Pino doradas pintado en cada una dellos una figura de diferentes trages, hordinario, de antonio rriche" 47 , en el inventario de la Quinta Real de La Ribera de Valladolid en 1607, podrían hacer pensar en una estadía efectiva de Antonio Ricci en Valladolid, tal y como afirmaba Pedro de Madrazo ${ }^{48}$.

Del mes de agosto de 1607 es la noticia de su presencia como fiador sobre una bula del monasterio bernardo de Vaix, donde de nuevo se cita a Antonio Ricci viviendo en casas propias de la Carrera de San Jerónimo ${ }^{49}$, una de las cuales venderá junto a su mujer al año siguiente ${ }^{50}$. Hacia 1609 se ha fechado un posible retrato de su mano de Margarita de Austria, de nuevo para el Colegio del Corpus Christi ${ }^{51}$, mientras en marzo de 1610 se le requiere para cobrar la deuda

cendimiento de la Cruz; los que la miran no dificultan su autor porque sacan por la mano ser de D. Francisco Rizi", recogido en SÁnchez CANTón, F. J., op. cit., vol. V, pp. 492-3; sobre la historia del convento, Aparisi Laporta, L. M., Convento de Nuestra Señora de la Victoria, Madrid, 2000, recoge otras descripciones como las de Gil González de Ávila, Gerónimo Quintana o Antonio Ponz.

46 26-9-1606, en PÉrez PASTOR, C., op. cit., pp. 118-119; en A.H.P.M., ante el escribano Diego Ruiz de Tapia, protocolo n. ${ }^{\circ} 2269$, fol. 994.

47 FLorit, J. M., "Inventario de los cuadros y otros objetos de Arte de la quinta real llamada 'La Ribera' en Valladolid", en Boletín de la Sociedad Española de Excursiones, 1906, p. 155. Las obras permanecen igualmente en 1619, A.G.P.R.M. Sección administrativa. Oficios de la Real Casa, Legajo 902, fol. 4 s.n., citado en ANGUlo ÍñIguEZ, D. y PÉREZ SÁNCHEZ, A. E., op. cit., pp. 58-59 y 64.

48 De Madrazo, P., op. cit., pp. 96 y 101.

49 A.H.P.M., protocolo n. ${ }^{\circ} 1195,17 / 8 / 1607$, en Agulló y Cово y CoBO, M., Noticias sobre pintores madrileños de los siglos XVI y XVII, Granada, 1978, pp. 134-135; MARÍAs Franco, F., op. cit., p. 27, relaciona este hecho con la posterior llegada de su hijo Juan Andrés al monasterio de Montserrat. Pero es evidente que la documentación conservada revela que la actividad de Antonio Ricci se quedó en la figura de fiador. No hay justificación para creer que este suceso pudiera motivar la llegada del hijo pintor a otra abadía catalana nada menos que veinte años después. Pero, además, nada tenía que ver la abadía cisterciense de Vaix, con la benedictina de Montserrat, pues ésta formaba parte de la Congregación de San Benito de Valladolid. Es necesario conocer el desarrollo de la historia de la abadía de Montserrat para advertir que su situación de abadía señera de Cataluña pero perteneciente a la congregación castellana, motivó en buena medida la recepción de monjes castellanos y, en especial madrileños, pues éstos debían profesar en su gran mayoría fuera de la Corte ya que el único monasterio benedictino de aquellos años en Madrid, San Martín, estaba copado por los altos dignatarios de la orden que debían estar cerca del centro del poder, por lo que este monasterio normalmente sólo admitía a legos, además, un acuerdo obligaba a mantener un número equivalente de monjes catalanes y castellanos en el monasterio de Montserrat, lo que obligaba al frecuente desembarco de profesos castellanos allí y explicaría la llegada del pintor Juan Andrés Ricci; sobre el tema, ver GaRCía LóPEZ, D., op. cit.

50 "Papeletas sobre pintores", en Boletín del Seminario de Estudios de Arte y Arqueología, 1966, pp. 430-3 (p. 432); el documento en A.H.P.M., protocolo n. ${ }^{\circ}$ 2631, fol. 40.

51 Benito Doménech, F., Pintura y pintores..., op. cit., n. ${ }^{\circ}$ 223, pp. 313-314. 
que le había llevado a la cárcel y de la que había salido gracias a una fianza ${ }^{52}$. En octubre de este mismo año realiza la tasación de pinturas a la muerte de doña Ana Díaz de Villegas, mujer de Agustín de Villanueva, secretario de Su Majestad y Conservador General de los Reinos de la Corona de Aragón, padres del posteriormente poderosísimo protonotario de Aragón, don Jerónimo de Villanueva ${ }^{53}$. Éste encargará de nuevo a Antonio Ricci el inventario de las pinturas a la muerte de su padre, que el pintor firma el diecisiete de enero de $1621^{54}$. En febrero de 1611, Antonio Ricci recibió el pago por setenta y dos planchitas con nueve coros de ángeles realizados para la duquesa de Uceda" ${ }^{55}$. Mientras que en mayo de 1613 ya es citado como "visitador general de la limpieça de las calles desta Corte" ${ }^{26}$. No debió de ser mucho antes su nombramiento para este puesto pues, como se verá seguidamente, en mayo de 1633 decía haber perdido, parece que recientemente, esta plaza "de La Limpieça en que auia seruido veinte años". Seguramente comenzaría esta labor alrededor de 1612, pues en enero de este año firma una carta de pago por la que declara haber recibido 5.163 reales "por tres carros para la limpieza de la calle nueva" 57 . Tal y como describen los contemporáneos las calles de Madrid, la tarea no debía de ser nada sencilla, en todo caso se resaltaba la necesidad imperiosa de la frecuente higiene de las vías urbanas matritenses como único medio para luchar contra su constante menoscabo, tal y como contaba durante su estancia en la Corte el nuncio extraordinario Camilo Borguese, el futuro Papa Paulo $\mathrm{V}^{58}$.

Esta actividad en la limpieza de las calles se vuelve a citar en febrero de 1616 cuando Antonio Ricci aparece como testigo de Pompeyo Leoni para que se reconozca a éste como hijo natural del conocido escultor italiano Pompeo Leoni (1533-1608) y la milanesa Ginera Vila ${ }^{59}$. Ricci ya había retratado al padre Pompeo tal y como aparece en el inventario de $1609^{60}$. En 1616 a Antonio Ricci se le describe como pintor, vecino de Madrid, "que vive en sus casas de la Carrera de San Jerónimo, y tiene oficio de república de visitador general de la limpieza y empedrado desta parte por su Majestad"61. Es interesante el que se haga mención en este caso de sus dos empleos, como funcionario de limpieza y pintor, para desmentir las frecuentes afirmaciones según las cuales habría abandonado tempranamente la pintura ${ }^{62}$. Como testimonio manifiesto se pueden contemplar los dos magníficos retratos de los duques de Ciriza, don Juan de Ciriza -miembro

52 4/3/1610, en Pérez PASTOR, C., op. cit., p. 130.

53 A.H.P.M. Prot. 1826, fols. 853-858; citado en Agulló y CoBo, M., op. cit., p. 135.

54 A.H.P.M. Prot. 2028, fols. 745v.-753; citado en Burke, M. B. y CHERrY, P., Spanish inventories. Collections of Paintings in Madrid 1601-1755, Nueva York, 1997, I, pp. 220-224.

55 12/2/1611, en Pérez Pastor, C., op. cit., p. 134.

56 Agulló y Cobo, M., Más noticias sobre pintores madrileños de los siglos XVI al XVII, Madrid, 1981, p. 171.

57 A.H.P.M., protocolo 3110, 27-1-1612.

58 "Diario de la relación del Viaje de Monseñor Camilo Borghese", en García MerCada, J., Viajes de extranjeros por España y Portugal, Madrid, 1952, t. I, p. 1472, "Las casas [de Madrid] son malas y feas, y hechas casi todas de tierra, y, entre las otras imperfecciones, no tiene aceras ni letrinas: por lo que todos hacen sus necesidades en los orinales, los cuales tiran después a la calle, cosa que produce un hedor insoportable; y ha obrado bien la Naturaleza, que en aquella parte las cosas odoríferas están en abundancia, que de otro modo no se podría vivir: donde si no se usase diligencia para limpiar frecuentemente la calle no se podría andar, aunque a pesar de eso no es posible andar de pie".

59 Estella, M., "Los Leoni, escultores entre Italia y España", en URReA, J. (dir.): Cat. Exp. Los Leoni (1509-1608). Escultores del Renacimiento italiano al servicio de la corte de España, Madrid, 1994, pp. 29-62 (p. 43).

${ }^{60}$ Marqués de Saltillo, "La herencia de Pompeo Leoni”, en Boletín de la Sociedad Española de Excursiones, t. XLII, 1934, pp. 95 y ss.; Angulo Íñiguez, D. y Pérez SÁnchez, A. E., op. cit., p. 64; M. Estella, op. cit., p. 47.

${ }^{61}$ 22-2-1616, en Pérez Pastor, C., op. cit., p. 152.

${ }^{62}$ Es una opinión repetida muy frecuentemente, quizá desde la rotunda afirmación de SÁNCHEZ CANTÓN, F. J., Los pintores de cámara de los reyes de España, Madrid, 1916, p. 91, nota n. ${ }^{\circ}$ 3: "una vez despedido de San Lorenzo, tuvo el buen acuerdo de dejar descansar los pinceles, y dedicó su actividad a muy variados trabajos de ingeniería y fontanería". 
del Consejo Supremo de Guerra e importante personaje sobre todo en la corte de Felipe III- y su esposa doña Catalina de Alvarado, firmados por Antonio Ricci en 1617 (“Antonius Rizzi Fa. Anno 1617"). Se conservan en el convento de las agustinas recoletas de Pamplona junto a obras de Orazio Borgianni, Francisco Camilo y Pedro de Villafranca, un escenario para el que también trabajaron Vicente Carducho y Eugenio Cajés ${ }^{63}$.

Se trata, con diferencia, de las mejores pinturas conservadas de Antonio Ricci, obras que entroncan con lo más aventajado de la retratística contemporánea. Su alta calidad ha servido para que en los últimos tiempos se haya especulado sobre la atribución a Antonio Ricci de otras pinturas del entorno de los retratistas de Corte, como un lienzo que representa a una Dama española de la National Gallery of Ireland o un retrato de la reina Isabel de Borbón del Museo del Prado $^{64}$. En todo caso, parecen atribuciones difíciles de probar con seguridad al hacerse sobre bases básicamente formalistas. Hay que tener en cuenta dos serias y principales objeciones: el variado número de retratistas cortesanos que trabajaban contemporáneamente, ajustados a un patrón de efigie regia plenamente asentado por esos años, que les lleva a seguirlo unánimemente más que a distinguirse de forma individual $\mathrm{y}$, por otro lado, la gran disparidad en el estilo del propio Ricci en las obras que conocemos de su mano: desde la paupérrima calidad de los lienzos para el Colegio del Corpus Christi a la más que notable de los retratos de los Ciriza ${ }^{65}$. En todo caso es evidente que Antonio Ricci pintó no sólo para el ámbito regio sino que también contó con numerosos clientes particulares y cuadros suyos se guardaban en varias colecciones madrileñas. Además del citado retrato regio que guardaba el capitán Jerónimo de Soto, podemos comprobar que Ricci también siguió la moda de las madonas de Correggio tal y como muestra la pintura citada en el inventario de Sebastián Díaz de Ontiveros y Ana María Núñez de Cos, que en 1639 detallaba "otro quadro de nra $\mathrm{s}^{\text {ra }}$ de la leche de una bara de cayda copia de la coreco [Correggio] de mano de antonio riche"66. También había un cuadro suyo, concretamente un San Agustín, en el primer altar del lado de la Epístola en el convento de Santo Domingo el Real de Madrid, la única obra pública que se conocía de su mano tal y como citan las fuentes ${ }^{67}$. Nos podemos hacer

63 Segovia Villar, M. C., "El convento de Agustinas Recoletas de Pamplona", en Boletín del Seminario de Arte y Arqueología, 1980, pp. 255-284; García GaInZA, M. C. (dir.), Catálogo monumental de Navarra, t. V-1, Pamplona, 1994, p. XXXI; Ibid., t. V-3, 1997, pp. 324-5; AzANZA LóPEZ, J. J., "Lectura emblemática de dos retratos de Antonio Ricci en las Agustinas Recoletas de Pamplona", en VI Congreso Internacional de Emblemática, La Coruña (2002), 2004, pp. 155-165; Jordan, W. B., Cat. Exp. Juan Van der Hamen y León y la Corte de Madrid, Madrid, Patrimonio Nacional, 2005, p. 27.

64 Diéguez Rodríguez, A., "Un retrato de Isabel de Borbón de Museo del Prado posible obra de Antonio Ricci”, en Goya, 2003, pp. 256-262; sobre la obra de Dublín, la autora recoge la interpretación de CARDERERA, V., Catálogo de retratos antiguos de personajes ilustres españoles y estranjeros..., Madrid, 1877, n. ${ }^{\circ}$ 73, pp. 27-28: "Estilo de Pantoja, pero superior en mérito; por la firmeza de ejecución y pasta de color podría atribuirse á Antonio Ricci” (p. 28); después Mayer fue el primero que hizo referencia a la similitud de estilos entre la obras de la National Gallery y El Prado, véase Mulcahy, R., Spanish Paintings in the National Gallery of Ireland, Dublín, 1988, pp. 37-39, autora que sin embargo cree difícil ver alguna conexión con la obra conocida de Ricci.

${ }^{65}$ Por otro lado, si se pudiera considerar el resultado de una "evolución" del pintor a lo largo de su carrera, desmentiría el argumento principal de DiÉGuez Rodríguez, A., op. cit., quien se basa en la posible formación italiana del artista como el elemento diferenciador de su arte con respecto a los otros retratistas coetáneos.

${ }^{66}$ Burke, M. B. y Cherry, P., op. cit., I, p. 330; además, en el siglo XIX, el Conde de la Viñaza identificaba un Retrato de la duquesa del Infantado obra de Ricci en la colección del duque de Osuna, CONDE DE LA VIÑAZA, Adiciones al Diccionario Histórico de los más ilustres profesores de las Bellas Artes en España de D. Juan Agustín Cean Bermúdez..., Madrid, Imprenta y Litrografía de los Huérfanos, 1894, t. III, p. 313.

${ }^{67}$ Ponz, A., Viage de España, en que se da noticia De las cosas más apreciables, y dignas de saberse, que hay en ella, 3. a ed., Madrid, Viuda de Ibarra (1787-1894, 18 vols.) V, p. 466; CEÁn BERMÚDEZ, J. A., op. cit., IV, p. 203; Ceán también lo cita en su manuscrita "Historia del Arte de la Pintura por D. Juan Agustin de Cean Bermudez", 1824, 
una idea de este tipo de pinturas religiosas a través de la conservada Magdalena penitente firmada por Ricci, donde se evidencia su cercanía a artistas contemporáneos como Luis de Carvajal ${ }^{68}$.

En 1618 se fecha el remate de unas casas a favor de Antonio Ricci ${ }^{69}$ mientras al año siguiente recibe el pago de doscientos ducados por algunas pinturas que había hecho para Domingo Navarro, criado de su Majestad ya fallecido, que le sirven para salir de la cárcel, a la que había sido conducido precisamente por el retraso de los testamentarios en la ejecución de su cuenta ${ }^{70}$. Aquí aparece ya relacionado con Francisco Guillamas Velázquez, ayuda de cámara de su Majestad, con quien más tarde se verá precipitado a la ruina económica. Ese mismo año vende unas casas en la calle de San Luis ${ }^{71}$. El quince de junio de 1620 se procede a la renovación de su contrato para la limpieza y empedrado de las calles de Madrid por seis años ${ }^{72}$. En enero de 1621 lo hemos visto firmando el inventario de los cuadros realizado a la muerte de Agustín de Villanueva y en 1622 compra varias piezas de oro junto a su mujer, Gabriela de Guevara ${ }^{73}$. En 1625 aparece citado en la segunda parte de la obra literaria de Alonso Castillo Solórzano Donayres del Parnaso, donde se hace referencia a su empleo en la limpieza de las calzadas públicas:
"Pasó la calle Mayor
que tantos lodos produce
con que a Riche le excusó
de limpiar sus servidumbres" 74

Hasta julio de 1630 no se vuelven a tener noticias de Antonio Ricci, cuando de nuevo había estado en la cárcel y termina de pagar una deuda a Pelegro Solimano, al que anteriormente había entregado como prenda varios cuadros y otros elementos que parecen utilizados en experimentos alquímicos ${ }^{75}$. Una actividad que Antonio Ricci practicó por esos años. Hay que recordar que la alquimia vivía una auténtica floración en la España contemporánea: ya durante el siglo XVI incluso Felipe II había tenido a su servicio todo un grupo de ensayistas, y el Conde-Duque de Olivares también aparece identificado a menudo como aficionado a estas actividades. De lo frecuente que éstas eran en la época da cuenta su abundante reflejo en la literatura, ya sea en forma crítica o simplemente paródica de estos "monopantos" como los calificaba Quevedo ${ }^{76}$.

Antonio Ricci debió de perseverar en la búsqueda de la fórmula recóndita, quizá como consecuencia de los problemas económicos que en poco tiempo le llevarían a la ruina. Así, en 1631, se muestra ilusionado por estar cercano al objetivo de conseguir la destilación de la plata,

B.N.M. Mss. 21.456/1, tomo VI. [copia del manuscrito depositado en la Biblioteca de la Real Academia de San Fernando] p. 101; ANGUlo Í̃̃IgueZ, D. y PÉrez SÁncheZ, A. E., op. cit., p. 63.

68 Angulo Íñiguez, D. y Pérez SÁnchez, A. E., op. cit., pp. 59 y 63

69 22-5-1618, en Pérez Pastor, C., op. cit., p. 159.

70 13-1-1619, en PÉrez PAstor, C., op. cit., p. 160.

71 Agulló y Совo, M., “Antonio y Francisco Rizzi”, en Anales del Instituto de Estudios Madrileños, 1996, pp. 7597 (pp. 85-86).

72 "Condiciones para la limpieza y empedrado de las calles de Madrid por 6 años", recogido en PÉrez PASTOR, C., Bibliografía madrileña o descripción de las obras impresas en Madrid, Madrid, 1891-1907, II, p. 522.

73 23/1/1622, A.H.P.M., ante el escribano Ruiz de Tapia, protocolo n. ${ }^{\circ} 2325$, s.f.

74 Citado en Pérez Pastor, C., Bibliografía madrileña..., op. cit., Parte III, p. 264; y también en Sánchez Cantón, F. J., Fuentes literarias..., op. cit., t. V, p. 459.

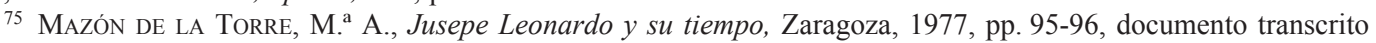
en p. 417.

76 García Font, J., Historia de la alquimia en España, ed. Barcelona, 1995, especialmente pp. 167 y ss.; LóPEZ Pérez, M., Asclepio renovado. Alquimia y Medicina en la España Moderna (1500-1700), Madrid, 2003; asimismo, sigue siendo fundamental DE LuANCO, J. R., La alquimia en España. Escritos inéditos, noticias y apuntamientos que pueden servir para la historia de los adeptos españoles, Barcelona, 1889-1897, 2 vols. 
según se constata en su carta de enero de ese año en la que felicita la Pascua a don Alonso de Villegas ${ }^{77}$. Por esta misiva, además, podemos comprobar que Ricci es un hombre letrado que se expresa con facilidad a través de la palabra escrita. Como dice Martí Monsó, es complicado establecer si el destinatario de la misiva sería el conocido escritor toledano Alonso de Villegas Selvago, nacido en 1534 y del que se desconoce la fecha de su muerte, aunque Nicolás Antonio date parte de su producción entre 1635 y $1637^{78}$. Parece señalar en esta dirección el que el pintor Diego Valentín Díaz definiese al destinatario de la carta, al dorso de ésta, como "D. Alonso de Villegas singular ingenio de España"79. El documento es además interesante al registrarse de nuevo la relación de Antonio Ricci con varios personajes de la Corte, como el "Capitan Tomas de Cardona Maestro de la Camara del Rey Nuestro Señor" o el "Sr. Martin de Soto ensayador general de las minas de españa”, aficionados como él a la alquimia. Además, da cuenta de que sigue viviendo en sus casas de la Carrera de San Jerónimo, frente a la calle del Lobo, y parece señalar ya una circunstancia que veremos seguidamente y que provocará su bancarrota económica: la pérdida de su puesto para la limpieza de las calles de Madrid, pues se refiere a él como el "officio publico que yo tenia".

A partir de aquí los problemas económicos no dejarán de acuciar al pintor. En junio de 1632, Antonio Ricci, junto a su mujer, se compromete a pagar 2.000 ducados al italiano Juan Enrique de $\mathrm{Carpi}^{80}$, y en enero del año siguiente ambos cónyuges firman una obligación sobre el dinero que les fue prestado ${ }^{81}$. En mayo de 1633 la bancarrota de Antonio Ricci es ya irremediable ante la imposibilidad de hacer frente a un censo firmado por el citado don Francisco de Guillamas Velázquez, antiguo ayuda de cámara de su Majestad, que fue sustituido e investigado por su trabajo en la Corte a partir de $1623^{82}$. La ruina posterior de Francisco Guillamas arrastró a Antonio Ricci, al tener éste "un censo de quatro mill ducados en plata que el dicho antonio Ricci deue al dicho francisco de guillamas cuyo derecho tiene nuestra R[ea]l Hacienda" ${ }^{83}$. Es en este proceso cuando Ricci indica que su mala situación financiera se debe "respeto de las necessidades del tiempo y verle quitado el officio que crio de La Limpieça en que auia seruido veinte años auian uenido en tanta quiebra de sus bienes que auia causado todos los deuitos" ${ }^{\text {" }}$. Por lo que aun pudiendo establecerse que se hubiese quitado este oficio público poco tiempo antes de 1633, el comienzo de esta labor, según confesión propia, llevaría por lo menos hasta 1612.

El Real Consejo de Hacienda, deudor a la vez del dicho Guillamas Velázquez, confiscará los haberes del pintor para proceder a pública subasta "a los bienes del dicho antonio Riçci y todos los que pareçieren y se hallaren ser suyos los embargareis y hareis embargar y depossitar en personas abonadas y de satisfacçion y los hareis vender y rematar en quien mas por ellos diere para que de su valor se haga pago a nuestra $\mathrm{R}[\mathrm{e}$ ] 1 Haçienda de lo que se liquidare deuerla el dicho antonio Ricci" $" 85$. Al año siguiente se procedió efectivamente al embargo de las posesiones de Antonio Ricci y su mujer como consta en el expediente de los bienes de Francisco Guillamas por

77 Martí Monsó, J., Estudios histórico-artísticos relativos principalmente a Valladolid, Valladolid, 1898, pp. 636-7.

78 Antonio, N., Biblioteca Hispana Nueva, t. I, ed. Madrid, F.U.E., 1999, pp. 61-62.

79 Martí Monsó, J., op. cit., p. 637.

80 A.H.P.M., ante el escribano Diego de Escobar, protocolo n. ${ }^{\circ} 3829$, fol. 701, 20-6-1632.

81 A.H.P.M., ante el escribano Juan de Quintanilla, protocolo n. ${ }^{\circ} 3695,5-1-1633$, fols. 6-7v.

${ }^{82}$ Noticias de Madrid 1621-1627, ed. de Ángel González Palencia, Madrid, 1942, p. 51: “[22-3-1623] Este día juró el Conde de Gondomar por Consejero de Estado, y mandó su Majestad a Don Lorenzo de Cárdenas, Conde de la Puebla, su Mayordomo, tomase cuentas a Francisco Guillamas Velázquez, del Oficio que tuvo de Maestro de Cámara, y se dio dicho oficio a Don Manuel de Hinojosa, de la Orden de Santiago, Guarda que fue de Don Rodrigo Calderón".

83 Archivo General de Simancas (en adelante A.G.S.) Registro general del Sello, 31-5-1633, s.f.

${ }^{84}$ A.G.S. Registro general del Sello, 31-5-1633, s.f.

85 A.G.S. Registro general del Sello, 31-5-1633, s.f. 
"almoneda de los bienes muebles de los dichos Antonio Rici y su muger... en el año de 1634" y de los "alquileres de las cassas de los dichos Antonio Rici y su muger"

Este tropiezo parece que arruinó para siempre las finanzas de Antonio Ricci y su familia, privado de su empleo público y parece que igualmente sin encargos pictóricos que pudieran facilitarle remontar tan difícil situación. De ahí la información de marzo de 1635, en la que su esposa muere en la cárcel, donde se encontraba por deudas y "No hizo testamento por no tener de qué" 87 . No se la cita como viuda, por lo que Antonio Ricci podía encontrarse todavía con vida, aunque se ha pensado en su posible fallecimiento ese mismo año ${ }^{88}$.

En definitiva, se puede constatar que Antonio Ricci fue ante todo un pintor dedicado a la realización de retratos, tal y como fue conocido en su tiempo, aunque también compuso pintura religiosa, estando vinculado fundamentalmente al ámbito cortesano. Pero seguramente su actividad artística no le permitió poseer una economía demasiado saneada para su abundante familia, lo que quizá le llevaría a la realización de otras actividades complementarias. Así obtuvo el puesto para la limpieza de las calles de Madrid que, según su propia declaración, constituyó durante veinte años la fuente principal de sus ingresos, sin la que la familia entró en ruina. Pero ello no le hizo abandonar la pintura y de esta forma se presentó y fue conocido en todo momento como pintor. Es interesante constatar que además de por la práctica de la pintura, se interesó por otras facetas comunes al grupo de pintores italianos a los que pertenecía, especialmente en la necesidad de la creación de una academia de pintura en la Corte. Ello es muestra de que aunque en ocasiones no se mostrase muy venturoso en su ejercicio no por ello dejó de comprometerse por una idea liberal y docta del arte muy extendida entre los artistas contemporáneos que frecuentaban la corte española, idea que igualmente hicieron suya sus dos hijos pintores, fray Juan Andrés y Francisco Ricci.

DAVID GARCÍA LÓPEZ

86 A.G.S., Contadurías Generales, leg. 2163, s. f.

87 En Agulló y Cobo, M., Documentos para la historia de la pintura española, Madrid, 1994, p. 102.

88 Agulló y CoBo, M., “Antonio y Francisco...”, op. cit., p. 77, especula sobre su posible muerte ese mismo año, en que el volumen de 1635 del libro de Difuntos de la parroquia de San Sebastián ha desaparecido. Tampoco consta en el de la Parroquia de Santa Cruz que correspondía a la Cárcel de Corte, si hubiese fallecido en prisión. 